\title{
A UTILIZAÇÃO DE ANÁLISE MACROSCÓPICA DE NASCENTE COMO FERRAMENTA DE EDUCAÇÃO AMBIENTAL
}

\author{
Maria Carolina Beckauser ${ }^{1}$ \\ Paulo Nakashima ${ }^{2}$ \\ Luciana Moraes Silva ${ }^{3}$
}

Resumo: Esse estudo expõe uma prática de educação ambiental, desenvolvida com alunos do $7^{\circ}$ ano da educação básica, que objetivou conhecer a organização do espaço geográfico e o funcionamento da natureza e suas relações com a sociedade, identificando as ações antrópicas e suas consequências na nascente urbana do córrego Villa City, no município de Paranavaí-PR. Foi realizada uma análise macroscópica na área de estudo, examinada de acordo com o método do Guia de Avaliação da Qualidade das Águas, proposto por Dias (2004) e adaptado por Gomes et al. (2005). Constatou-se que as ações antrópicas impactaram os recursos hídricos locais, afetando as populações circunvizinhas.

Palavras-chave: Nascente Urbana; Ensino de Geografia; Paranavaí-PR.

${ }^{1}$ Mestranda em Geografia da Universidade Estadual de Maringá. E-mail: mariacarolinabeckhauser@hotmail.com.

2 Professor Doutor, em Geografia da Universidade Estadual de Maringá. E-mail: mrnakashima@gmail.com.

${ }^{3}$ Mestre em Educação da Universidade Estadual do Paraná - Campus Paranavaí. E-mail: luciana_moraess@hotmail.com 


\section{Introdução}

As problemáticas pautadas nos últimos tempos em torno das questões socioambientais vêm levando a sociedade a repensar o seu modelo de crescimento econômico e baseá-lo no princípio da sustentabilidade, para isso, a Educação Ambiental (EA) torna-se uma ferramenta valiosa.

O desenvolvimento e a expansão das áreas urbanas causam degradação dos recursos hídricos, principalmente por conta de sua fragilidade. No início do surgimento das cidades $^{4}$, os rios serviram de atrativos para a construção e crescimento urbano, porém esses ambientes evidenciam problemáticas como alagamento, deslizamento de encostas, erosão, assoreamento e aumento da quantidade de resíduos sólidos urbanos, que são causados ou potencializados pelo uso e ocupação inadequados.

As nascentes ${ }^{5}$ são vítimas do processo de rápida urbanização, em que a legislação ambiental, que garante a sua preservação ${ }^{6}$, foi driblada, fazendo com que ficassem esquecidas e, quando não, drenadas ou canalizadas. Por conseguinte, há uma demanda emergencial para que haja a preservação e conservação ${ }^{7}$ das nascentes na área urbana, pois são fundamentais para a manutenção dos cursos d'água $\mathrm{e}$, consequentemente, para as bacias hidrográficas, onde, a partir das nascentes, a água desses ambientes se renova.

A água é uma substância vital para a manutenção da vida na Terra. Garantir a quantidade, qualidade e disponibilidade dos recursos hídricos é um grande desafio. Sua gestão pode ser instituída de caráter de preservação, que mantém a integridade total, e de conservação de auxílio no desenvolvimento sustentável. Segundo BARTH (1999), com a gestão dos recursos hídricos, pretende-se equacionar e resolver a escassez de água por meio de processos integrados de planejamento e administração.

A problemática ambiental é indissociável à interferência antrópica. Desse modo, se faz adequado a utilização do termo impacto socioambiental ${ }^{8}$, pois, além de destacar o problema, evidencia o agente causador e sofredor, os quais não devem ser analisados isoladamente, mas sim de forma dinâmica e interligada.

\footnotetext{
${ }^{4}$ Um meio ambiente construído, que é o retrato da diversidade de classes, das diferenças de renda e dos modelos culturais (SANTOS, 1994).

5 A Resolução do CONAMA $n^{\circ}$ 004/85 define nascente como sendo local onde se verifica o aparecimento de água por afloramento do lençol freático (BRASIL, 2002).

6 Conjunto de métodos, procedimentos e políticas que visem a proteção a longo prazo das espécies, habitats e ecossistemas, além da manutenção dos processos ecológicos, prevenindo a simplificação dos sistemas naturais (BRASIL, 2000).

7 O manejo do uso humano da natureza, compreendendo a preservação, a manutenção, a utilização sustentável, a restauração e a recuperação do ambiente natural, para que possa produzir o maior benefício, em bases sustentáveis, às atuais gerações, mantendo seu potencial de satisfazer as necessidades e aspirações das gerações futuras, e garantindo a sobrevivência dos seres vivos em geral (BRASIL, 2000).

8 O ambiente faz parte da sociedade e a sociedade faz parte do ambiente (FILHO, 2007).
} 
Assim, a utilização da EA como ferramenta auxiliadora no processo de gestão de recursos naturais, principalmente os recursos hídricos, é de suma importância para garantir a qualidade de vida das pessoas. A partir do momento que o indivíduo é atuante no meio como modificador do espaço e ele compreende essa função, a EA norteia a relação do homem com a natureza de forma mais harmônica.

A escola precisa se capacitar para atender às novas demandas da sociedade e a inserção de questões de urgência social no currículo, além de possibilitar o ensino e a aprendizagem para garantir à pessoa condições de ser, de favorecer a compreensão da realidade e participação social, também possibilita o relacionamento com a realidade contemporânea e, em razão disso, a interação com o meio.

Conforme Santos (2008), a EA permite uma nova interação criadora em função do desenvolvimento de uma racionalidade ambiental. Quando a proposta é introduzir inovações educativas nas escolas, conforme sugerido nos Parâmetros Curriculares, a capacitação dos responsáveis pela execução dessas inovações é absolutamente imprescindível.

Para que a EA, portanto, surta efeitos positivos nas instituições de ensino e seja praticada de acordo com os seus objetivos legalmente assegurados, precisamos ter maior conhecimento sobre o seu sentido e a sua importância. Para isso, a introdução da dimensão ambiental no sistema educativo exige um novo modelo de professor: a formação é a chave da mudança que se propõe, tanto pelos novos papéis que os docentes terão de desempenhar no seu trabalho, quanto pela necessidade de que eles sejam os agentes transformadores de sua própria prática.

Tendo consciência disso, percebe-se a necessidade de trabalhar com a EA como um mecanismo de ensino-aprendizagem no processo de formação do indivíduo atuante na sociedade de forma crítica e com autonomia.

Conforme o exposto, este trabalho apresenta uma proposta de ensino em $E A$, desenvolvida com alunos do $7^{\circ}$ ano da educação básica, que objetivou conhecer a organização do espaço geográfico e o funcionamento da natureza e suas relações com a sociedade, identificando as ações antrópicas e suas consequências na nascente urbana do córrego Villa City, no município de Paranavaí-PR.

A EA foi a ferramenta principal para propor aos educandos uma nova postura, enquanto agente modificador do ambiente, por meio do conhecimento e das discussões propostas em torno das fragilidades socioambientais locais. 


\section{Materiais a Métodos}

Esse estudo utilizou uma análise macroscópica de uma nascente urbana e seu entorno de acordo com o método do Guia de Avaliação da Qualidade das Águas, proposto por Dias (2004) e adaptado por Gomes et al. (2005). Esses parâmetros foram todos tabelados e enquadrados nos padrões para qualificação (Tabela 1), obtendo a somatória de pontos obtidos.

Tabela 1: Quantificação da análise dos parâmetros macroscópicos.

\begin{tabular}{|c|c|c|c|c|c|c|}
\hline Cor da água & (1) & Escura & (2) & Clara & (3) & Transparente \\
\hline Odor & $(1)$ & Cheiro Forte & $(2)$ & Cheiro Fraco & (3) & Sem Cheiro \\
\hline Lixo ao redor & $(1)$ & Muito & (2) & Pouco & (3) & Sem Lixo \\
\hline $\begin{array}{l}\text { Materiais } \\
\text { flutuantes }\end{array}$ & (1) & Muito & (2) & Pouco & (3) & $\begin{array}{l}\text { Sem Materiais } \\
\text { Flutuantes }\end{array}$ \\
\hline Espuma & $(1)$ & Muita & (2) & Pouca & (3) & Sem Espumas \\
\hline Óleos & (1) & Muito & (2) & Pouco & (3) & Sem Óleos \\
\hline Esgoto & $(1)$ & $\begin{array}{l}\text { Esgoto } \\
\text { Doméstico }\end{array}$ & (2) & $\begin{array}{l}\text { Fluxo } \\
\text { Superficial }\end{array}$ & (3) & Sem Esgoto \\
\hline Vegetação & $(1)$ & $\begin{array}{l}\text { Alta } \\
\text { Degradação }\end{array}$ & (2) & $\begin{array}{l}\text { Baixa } \\
\text { Degradação }\end{array}$ & (3) & Preservada \\
\hline Uso por animais & $(1)$ & Presença & (2) & Apenas Marcas & (3) & Não Detectado \\
\hline Uso por humanos & $(1)$ & Presença & (2) & Apenas Marcas & (3) & Não Detectado \\
\hline Proteção & $(1)$ & $\begin{array}{l}\text { Sem } \\
\text { Proteção }\end{array}$ & (2) & $\begin{array}{l}\text { Com Proteção } \\
\text { (com acesso) }\end{array}$ & (3) & $\begin{array}{l}\text { Com Proteção } \\
\text { (sem acesso) }\end{array}$ \\
\hline $\begin{array}{l}\text { Proximidade com } \\
\text { residência }\end{array}$ & (1) & $\begin{array}{l}\text { Menos de } 50 \\
\text { metros }\end{array}$ & (2) & $\begin{array}{l}\text { Entre } 50 \text { e } 100 \\
\text { metros }\end{array}$ & (3) & $\begin{array}{l}\text { Mais de } 100 \\
\text { metros }\end{array}$ \\
\hline $\begin{array}{l}\text { Tipo de área de } \\
\text { inserção }\end{array}$ & $(1)$ & Ausente & (2) & $\begin{array}{l}\text { Propriedade } \\
\text { Privada }\end{array}$ & (3) & $\begin{array}{l}\text { Parques ou Áreas } \\
\text { Protegidas }\end{array}$ \\
\hline
\end{tabular}

Fonte: Dias (2004); adaptado Gomes et al. (2005).

A pontuação obtida na nascente foi comparada na tabela classificatória (Tabela 2), a qual indica o grau de preservação e a classe em que a nascente está enquadrada.

Tabela 2: Classificação do grau de preservação das nascentes conforme parâmetros macroscópicos.

\begin{tabular}{ccc}
\hline CLASSE & Grau de Preservação & Pontuação Final $^{*}$ \\
\hline A & Ótima & Entre 37 e 39 pontos \\
\hline B & Boa & Entre 34 e 36 pontos \\
C & Razoável & Entre 31 e 33 pontos \\
\hline D & Ruim & Entre 28 e 30 pontos \\
\hline E & Péssimo & Abaixo de 28 pontos
\end{tabular}

(*) Notas para os 13 parâmetros observados (através da somatória dos pontos obtidos na quantificação da análise macroscópica).

Fonte: Dias (2004); adaptado Gomes et al. (2005). 


\section{Descrição da área de estudo}

O município de Paranavaí está localizado no noroeste do Paraná, nas coordenadas de $23^{\circ} 05^{\prime} 00^{\prime \prime}$ Sul e $52^{\circ} 27^{\prime} 32^{\prime \prime}$ Oeste, conforme Figura 1, com uma extensão territorial de $1.202,151 \mathrm{~km}^{2}$ (IPARDES, 2018).

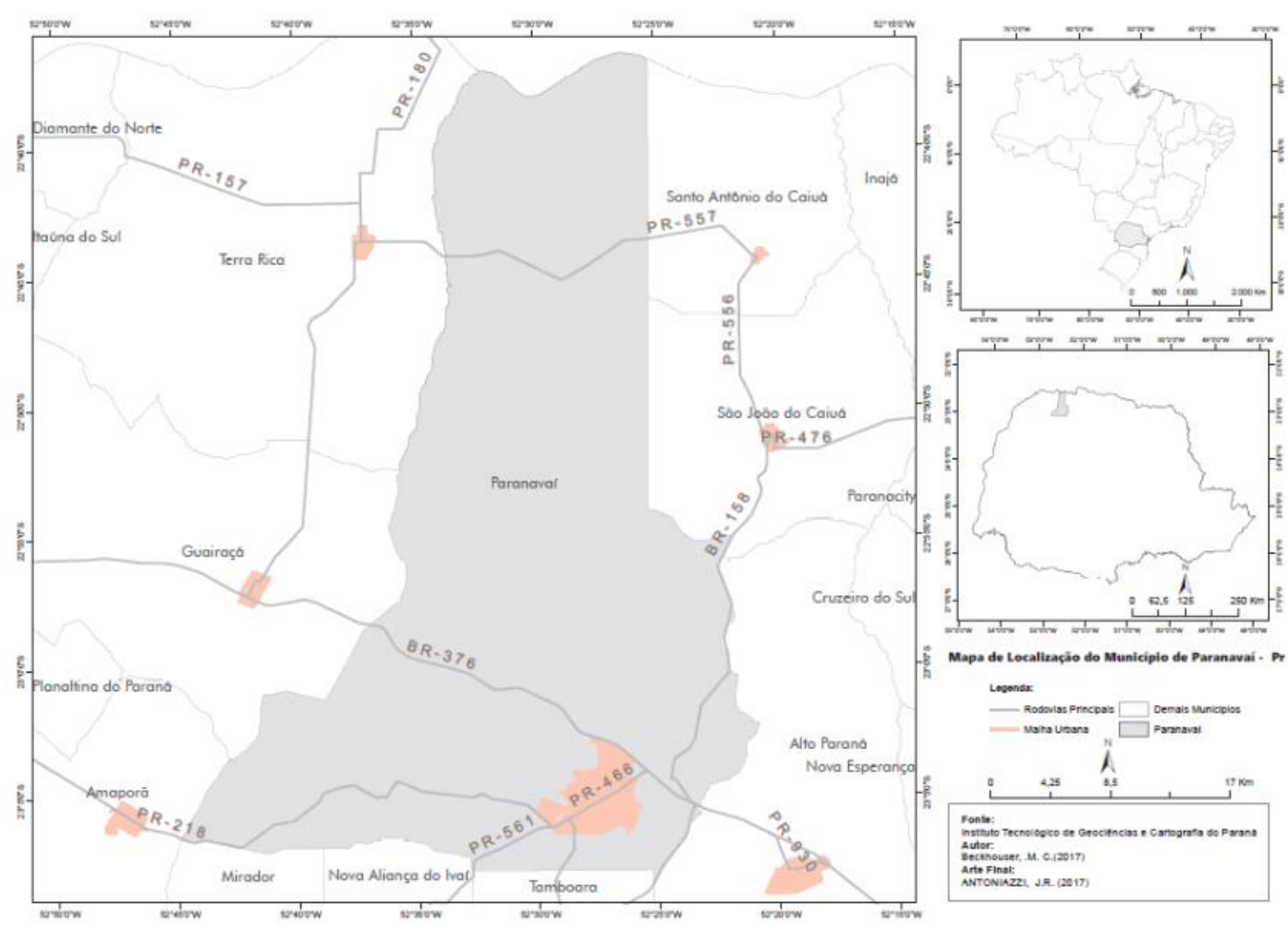

Figura 1: Localização do munícipio de Paranavaí - PR. Fonte: Elaborado pelos autores. (2018).

Baseado no Plano Diretor (2009), Paranavaí foi fundado em 1951 por meio de um processo de ocupação no norte do estado do Paraná com início em 1920 e foi intensificado em 1940, associado à cafeicultura paulista, em que as terras eram férteis e uma grande área organizada e imobiliária foi disponibilizada.

De acordo Maack (2012), o município situa-se no terceiro planalto do Paraná com um relevo plano da escarpa da Serra Geral, no subplanalto de Apucarana, com clima subtropical úmido mesotérmico $(\mathrm{Cfb})$ de verões quentes, geadas frequentes e sem estação seca com vegetação característica da floresta estacional semidecidual.

Stipp (2006) salienta que uma das fragilidades mais evidente do município é o solo. E muito comum presenciar na paisagem feições erosivas, graças à cobertura pedológica do Arenito Caiuá sobre um subplanalto de rochas de origens vulcânicas (basalto), possuindo um caráter mais arenoso e se tornando mais suscetível à presença de processos erosivos, sobretudo à erosão hídrica. 
Segundo o Plano Diretor (2009), o município em questão situa-se em um divisor de águas, entre a Bacia Hidrográfica do Ivaí e a Bacia Hidrográfica do Paranapanema. Sendo assim, é muito comum que haja a presença de córregos e nascentes no perímetro urbano, que estão, em sua grande maioria, impactadas pelo processo de urbanização.

A nascente urbana selecionada para aplicação da metodologia está localizada na Bacia do Ivaí, afluente do Ribeirão Paranavaí, pertencente ao Córrego Villa City. Essa escolha foi devido à proximidade com a escola onde a proposta de EA foi desenvolvida, conforme Figura 2.

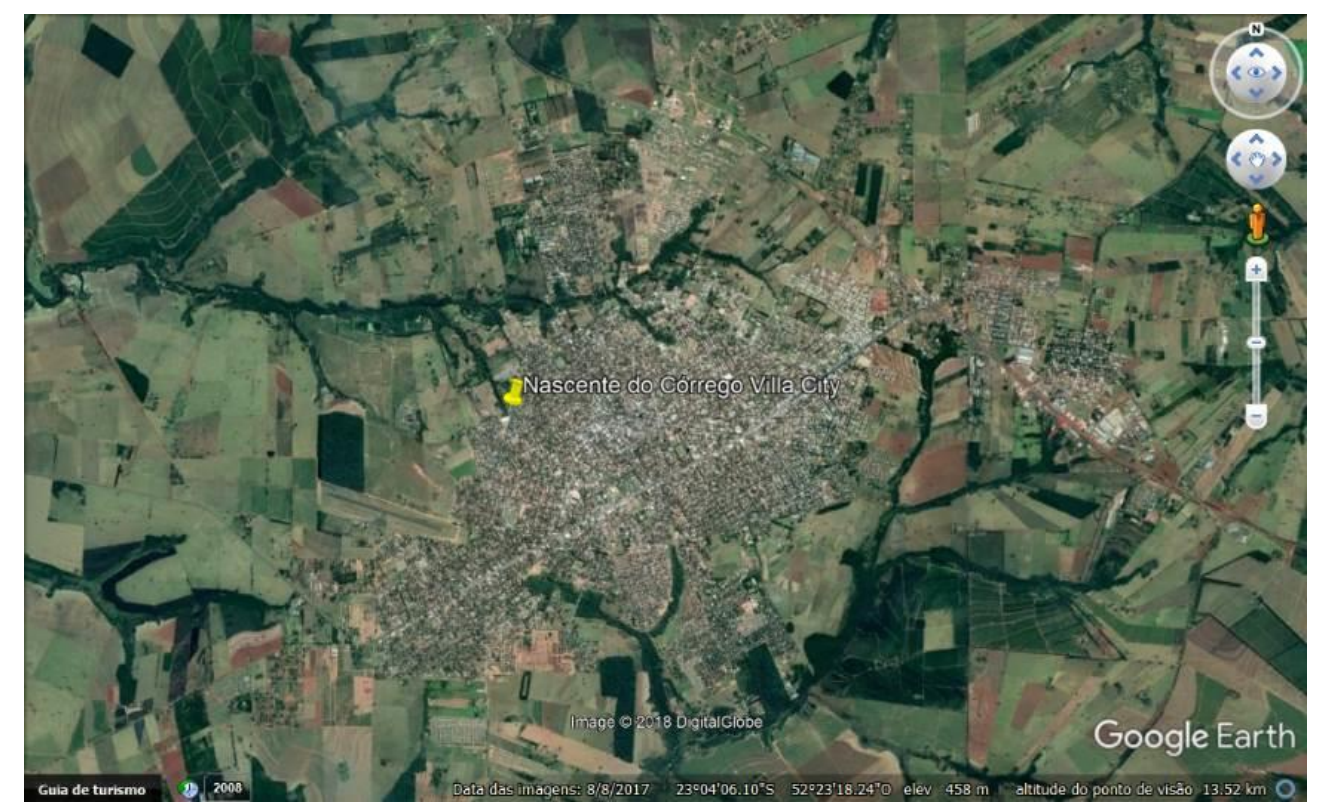

Figura 2: Localização da Nascente do Córrego Villa City em Paranavaí - PR.

Fonte: Google Earth, (2018).

Levando em consideração a citação feita por Biella e Costa (2002), a devastação dos recursos naturais, advindo com o processo de ocupação urbana, interfere também na dinâmica das microbacias hidrográficas urbanas, tendo como principal consequência o desenvolvimento da erosão hídrica como ravinas, voçoroca e erosão marginal, além do desaparecimento das nascentes incluídas nessa região.

As colocações destacadas por Biella e Costa (2002) estão de acordo com a realidade da área de estudo, onde o solo é arenoso e muito suscetível à existência de processos erosivos, o que exige muito mais cuidado por parte dos governantes e da população.

Á área do estudo em questão localiza-se na zona periférica de Paranavaí e apresenta alguns problemas decorrentes do processo de urbanização, uso e ocupação do solo, que atingem diretamente a população local e indiretamente a 
população da cidade. Em períodos de intensas chuvas, as proximidades ficam alagadas. O local possui processos erosivos, vegetação degradada e com pastos destinados aos ruminantes nas mediações, além de servir para destino de lixo e entulhos. Todos esses fatores contribuíram para a seleção da área de estudo, além de aproximar os educandos com a realidade local.

\section{Aplicação da metodologia}

O estudo foi aplicado para uma turma de $7^{\circ}$ ano do ensino fundamental II, com 26 alunos. Durante as aulas de geografia, foram ministrados conteúdos sobre os solos (formação, qualidade e o uso e ocupação inadequados) e problemas ambientais urbanos (poluição de águas, enchentes e o lixo urbano). As aulas foram ministradas de forma expositiva e dialogada com auxílio de recursos audiovisuais e material didático.

A proposta de EA foi desenvolvida em duas etapas de aplicação, sendo elas: o planejamento e a execução, conforme figura 03.

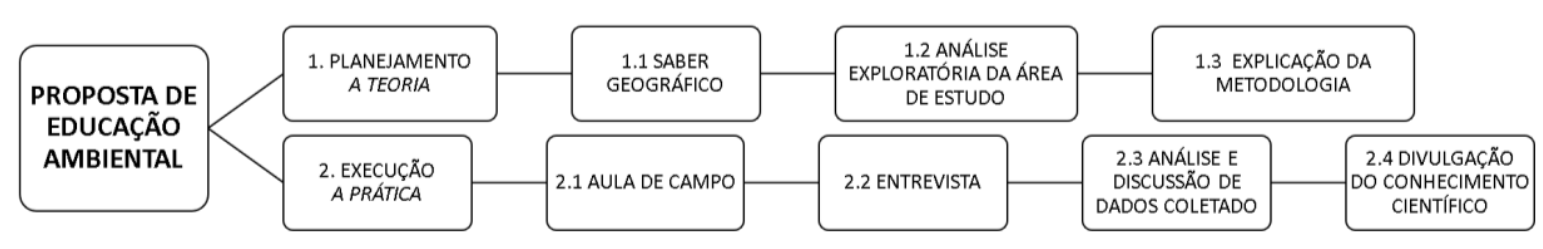

Figura 3: Fluxograma metodológico da proposta de EA aplicada a nascente do córrego Villa City.

Fonte: Elaborado pelos autores (2018).

$\mathrm{Na}$ fase referente ao Planejamento, iniciamos com aulas expositivas sobre o saber geográfico, posteriormente, houve a apresentação da área de estudo com o auxílio do Google Earth e, por fim, a explicação metodológica, esclarecendo o preenchimento da tabela de dados e questões dissertativas como: "1. Quais foram os problemas dos solos analisados no local? Explique cada um e como acontece. Quais as consequências e qual a situação atual in loco? Quais foram os outros problemas ambientais identificados na área de estudo? Especifique cada um, ressaltando a causa do surgimento e as consequências para o ambiente e para as pessoas. 3. Mediante observações de campo, verificamos uma série de problemas ambientais na área de estudo. Com base nessas observações e discussões realizadas em sala, aponte uma solução para tentar resolver ou minimizar a situação em questão.". Tais questionamentos serviram para que os educandos articulassem seus argumentos e conhecimentos sobre a proposta de EA em questão. 
Já na etapa referente à Execução, realizou-se o campo para verificar e analisar os impactos socioambientais da nascente urbana do córrego Villa City e seu entorno, conforme o método do Guia de Avaliação da Qualidade das Águas, proposto por Dias (2004) e adaptado por Gomes et al. (2005). Os alunos foram orientados a analisar os seguintes aspectos:

I. Coloração aparente da água, utilizando um recipiente plástico transparente para verificar a coloração da água distinguindo entre cor aparente e cor verdadeira; II. Odor da água, com uso de recipiente para coleta e verificação do odor; III. Lixo no entorno, presença de lixo no entorno da nascente e sua caracterização; IV. Materiais Flutuantes, presença de objetos flutuantes e sua caracterização; V. Espumas e óleo; verificação da presença na superfície; VI. Esgoto, presença de emissários; VII. Vegetação, caracterização próximo a nascente; VIII. Uso por animais, evidência de uso por animais, como pegadas, rastros, fezes, esqueletos e tocas; IX. Uso antrópico, evidência de uso por humanos, como trilhas ao redor da nascente, presença de bombas de sucção, irrigação e plantações ao redor; X. Proteção, existência de algum tipo de proteção ao redor da nascente, seja barreira natural ou artificial e sua caracterização; XI. Identificação, presença de placas ou similar que indiquem a existência de nascente no local; XII. Residências, quantificação aproximada em metros das residências, indústrias e estabelecimentos comerciais mais próximos até a nascente; XIII. Tipo de área de inserção, se a nascente está localizada em área que visa a preservação local (DIAS, 2004; adaptado GOMES et al., 2005, p. 106).

Em seguida, realizou-se a entrevista com os moradores das proximidades da área de estudo, assim os alunos puderam verificar e conhecer um pouco mais sobre a história de ocupação, contribuindo para enriquecer a coleta de dados dos educandos.

Retornando à escola, as informações coletadas e observadas foram analisadas e discutidas em grupo. Por fim, houve a divulgação dos dados para conscientizar a escola e a comunidade por meio de cartazes com fotos e resultados coletados na área de estudo.

\section{Resultados e Discussões}

No Planejamento da proposta de EA, na etapa 1.1 do Saber Geográfico, desenvolveram-se aulas expositivas de Geografia com os alunos do $7^{\circ}$ ano do Ensino Fundamental. Os conteúdos curriculares aplicados sobre o solo e os problemas socioambientais urbanos, foram associados pelos alunos a partir da presença de alguns eventos na área de estudo como erosão, degradação da 
vegetação, nascente e córregos impactados pela urbanização, deixando claro a fragilidade do município de Paranavaí-PR.

Durante os debates e apresentações dos conteúdos, os alunos perceberam a atuação antrópica como agente modificador do espaço natural e que algumas mudanças de atitudes poderiam surtir um efeito positivo nessa relação homemnatureza e, durante as discussões, sentiu-se a necessidade de realizar uma atividade prática, a fim de gerar uma consciência ambiental nos educandos.

Todo o planejamento de atividade e execução ocorreu com o auxílio da coordenação e consentimento dos pais e responsáveis pelos alunos. Na Execução da proposta de EA, na etapa 2.2 Aula de Campo, os problemas socioambientais urbanos foram evidenciados a partir do deslocamento do espaço escolar para a área de estudo. O percurso até a área de estudo foi realizado a pé e, durante o caminho, os alunos foram orientados a observar: a mudança de altitude; a declividade; o escoamento hídrico no relevo; proteção do espaço; o tipo de vegetação; a situação de conservação da nascente; a presença de resíduos e que tipo de resíduo (lixo ao redor, materiais flutuantes, espumas, óleos e esgotos); a utilização da área e o processo erosivo, conforme Figura 4.

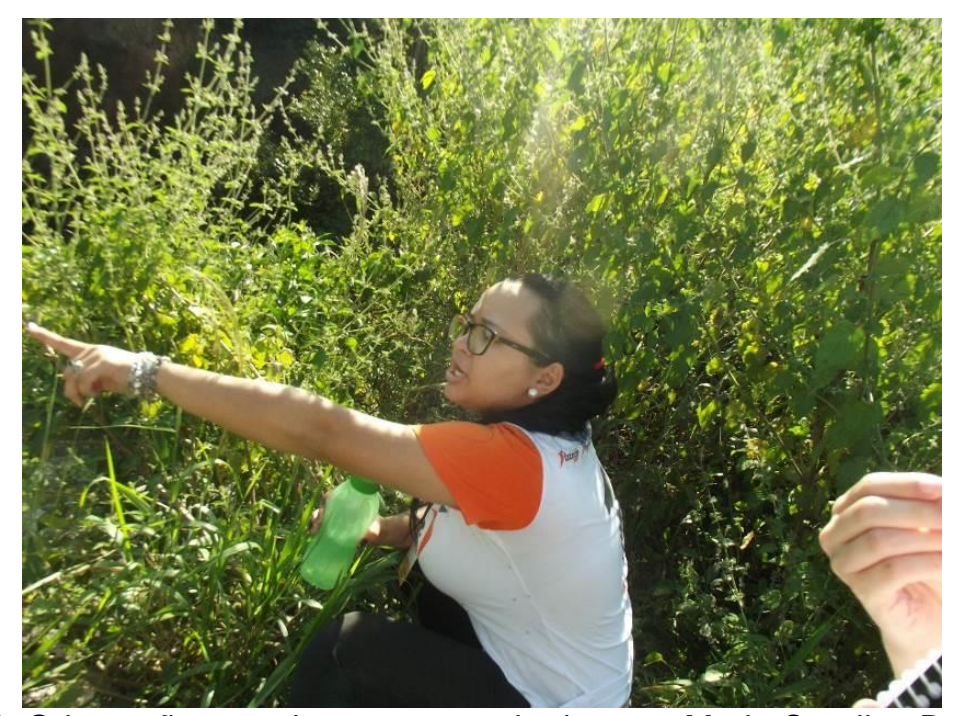

Figura 4: Orientações gerais expostas pela docente Maria Carolina Beckauser.

Fonte: Autores (2018).

Durante o trajeto, os alunos destacaram várias percepções, entre elas: a sucessão da paisagem cultural (escola) para a paisagem natural (nascente do Córrego Villa City) e a influência antrópica sobre esse espaço geográfico; a alteração microclimática na área de estudo, ou seja, os alunos sentiram que a temperatura entorno a nascente estava mais amena do que na escola por conta da predominância de elementos naturais (vegetação e recurso hídricos) ser maior 
que no ambiente escolar; e pontos de alagamentos ${ }^{9}$ durante o período de maior precipitação, testemunhados por alguns colegas que faziam uso das vias públicas nas mediações da área de estudo, onde foi relatado com déficit de escoamento da chuva.

No tabelamento quantitativo dos dados, os alunos foram estimulados a refletir sobre as características dos aspectos socioambientais do local, destacando as causas e consequências para o meio. Depois, eles foram divididos em grupos para quantificar os dados de acordo com o método do Guia de Avaliação da Qualidade das Águas, proposto por Dias (2004) e adaptado por Gomes et al. (2005), conforme Figuras 5 e 6.

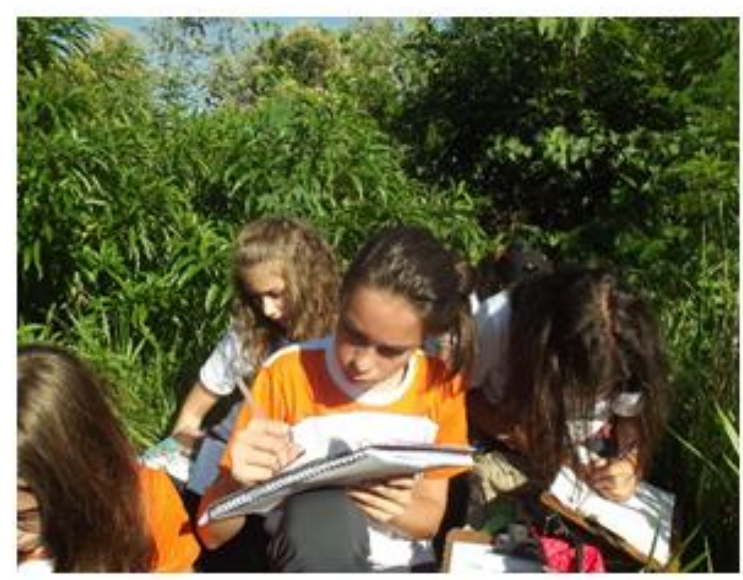

Figura 5: Grupo A quantificando os dados na tabela. Fonte: Autores (2018).

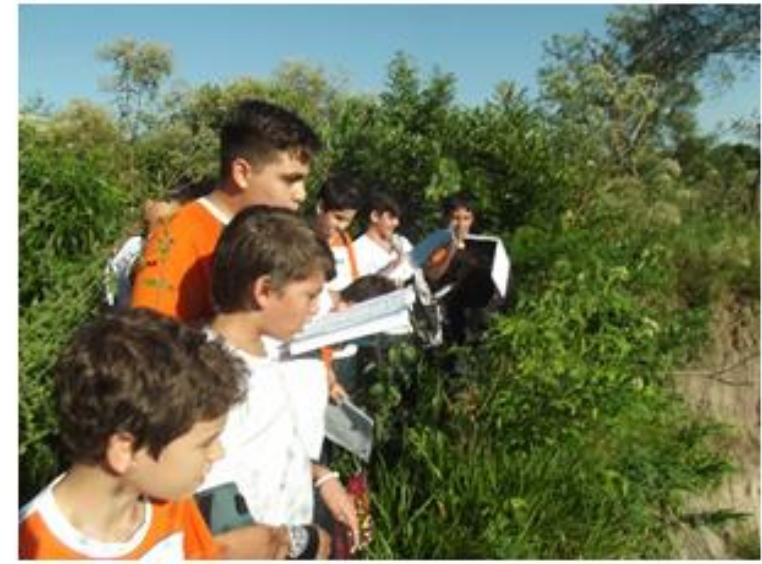

Figura 6: Grupo B quantificando os dados na tabela.Flonte: Autores (2018).

Durante a atividade de campo, os moradores ficaram curiosos com a movimentação e vieram verificar o que estava acontecendo. Após os devidos esclarecimentos por parte da docente responsável pela proposta de EA, a população se interessou pelo assunto e relatou diversas problemáticas que envolviam a área de estudo e alguns acontecimentos históricos e medidas tomadas pelo poder público para tentar minimizar a degradação daquela área, conforme Figura 7.

${ }^{9}$ ALAGAMENTO: acúmulo de água decorrente da deficiência do sistema de drenagem (AMARAL e RIBEIRO, 2009). 


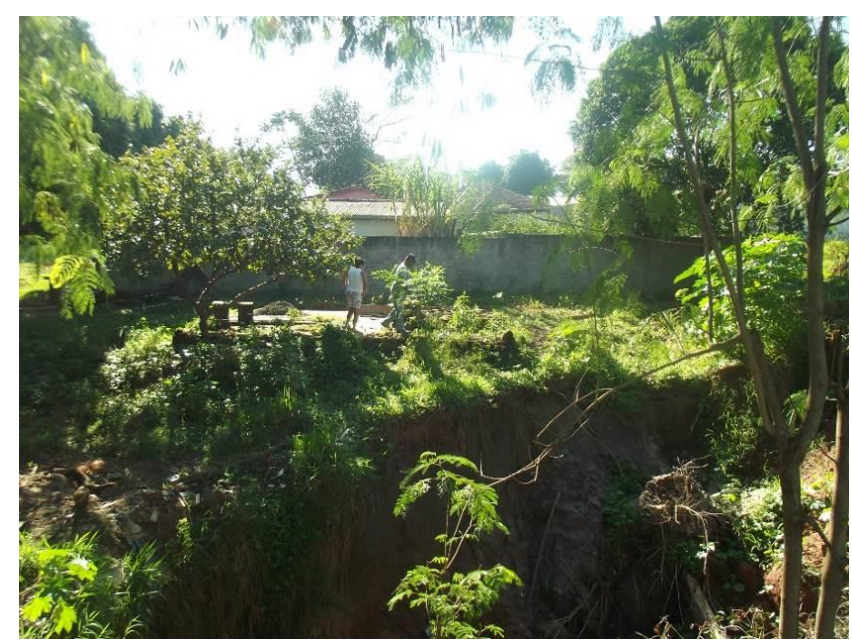

Figura 7: Moradores relatando algumas informações sobre a área de estudo, na vertente leste.

Fonte: Autores (2018).

Os alunos participaram ativamente da entrevista realizando anotações, perguntas e comentários sobre os aspectos destacados pelos moradores.

Após a coleta de dados, depoimentos e fotografias em campo, retornamos à escola, onde os dados foram discutidos em grupos, inicialmente, de forma aleatória e, posteriormente, foram padronizados, conforme Figura 8, para caracterizar a nascente e discutir os dados quantitativos que foram representados na Tabela 3.

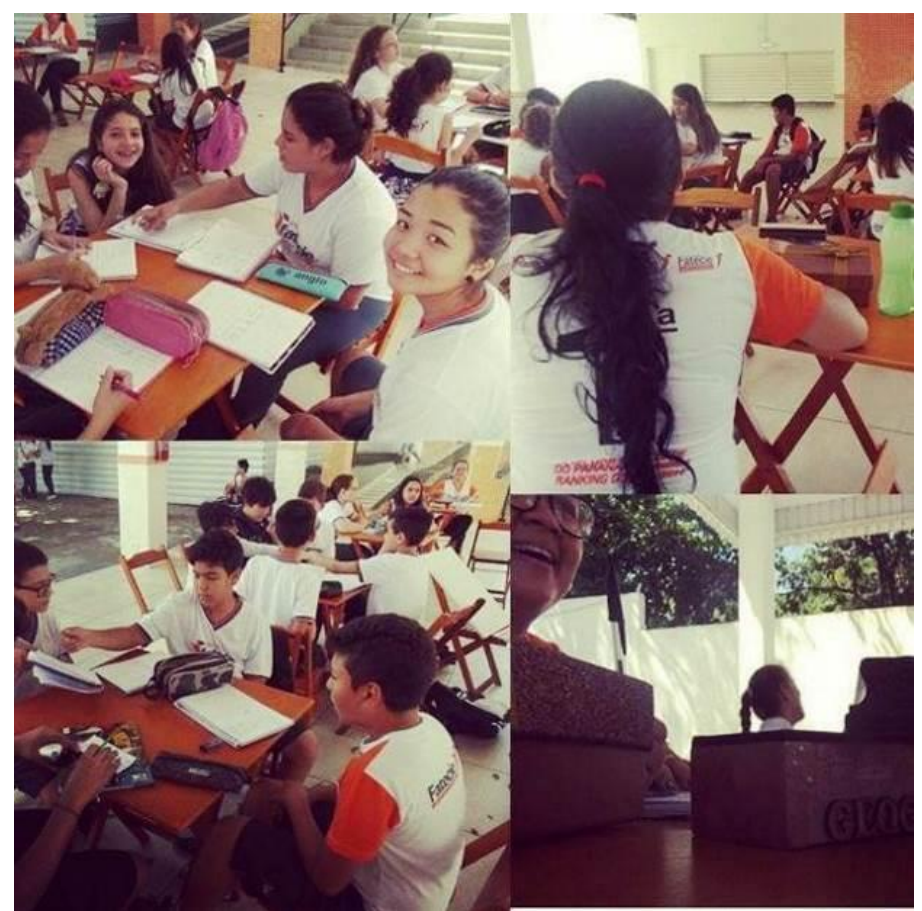

Figura 8: Análise e discussões de dados em grupo. Fonte: Autores (2018). 
Tabela 3: Classificação do Grau de Preservação da nascente do Córrego Villa City conforme parâmetros macroscópicos.

\begin{tabular}{l|l}
\hline \multicolumn{2}{c}{ Nascente do Córrego Villa City } \\
\hline Cor da água & 2 - Clara \\
Odor & 2 - Cheiro Fraco \\
Lixo ao redor & 1 - Muito \\
Materiais Flutuantes & 2 - Pouco \\
Espumas & 3 - Sem espumas \\
Óleos & 3 - Sem óleo \\
Esgotos & 3 - Sem esgoto \\
Vegetação & 1 - Alta degradação \\
Uso por animais & 2 - Apenas marcas \\
Uso por humanos & 1 - Presença \\
Proteção do Local & 2 - Com proteção (com acesso) \\
Proximidade com residência & 1 - Menos de 50 metros \\
Tipo de área de inserção & 1 - Ausente \\
Pontuação & $\mathbf{2 4}$ pontos \\
Qualidade & Péssimo \\
Enquadramento & Classe E \\
\hline
\end{tabular}

Fonte: Autores (2018).

Durante o tabelamento geral dos aspectos macroscópicos, foram discutidos diversos pontos observados, dentre eles o processo erosivo, conforme Figura 9. Esse fenômeno foi um dos mais destacados durante o debate, além de enfatizar as causas e consequências do impacto ambiental no solo, os alunos ainda propuseram possíveis soluções para minimizar ou controlar o avanço da erosão. Outro ponto ressalto foi a presença de lixo e entulhos no curso d'água e seu entorno.

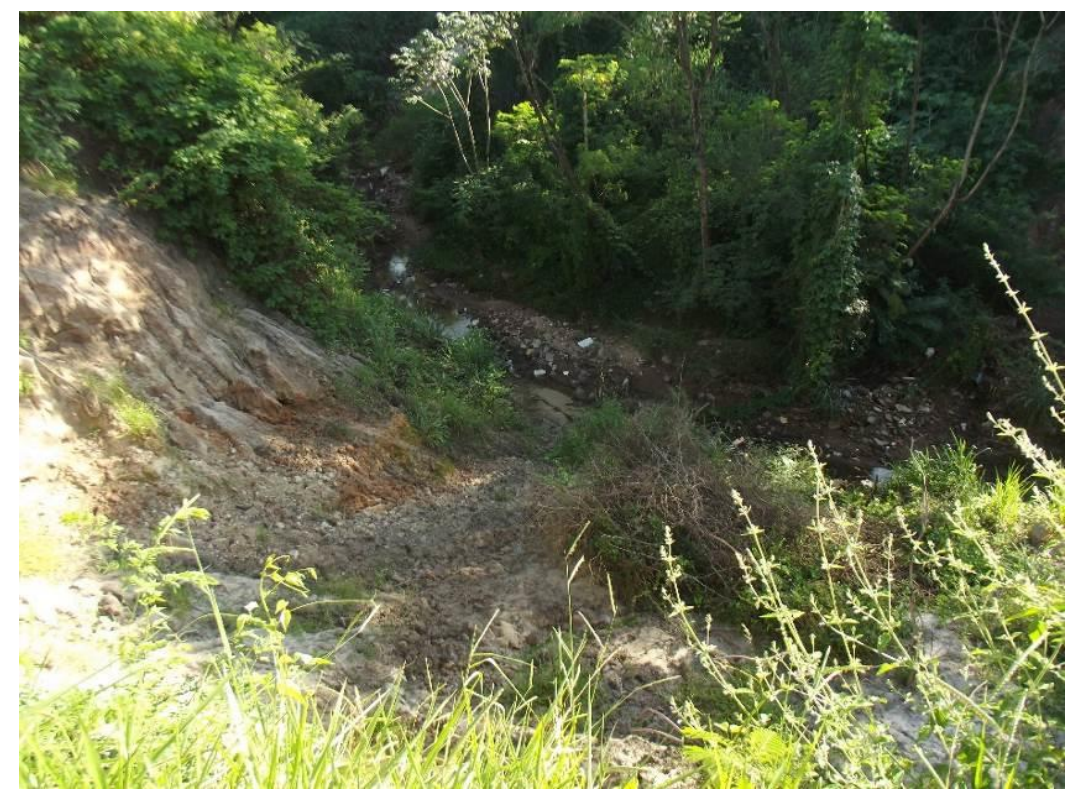

Figura 9: Processo erosivo no entorno da nascente do Córrego Villa City.

Fonte: Autores (2018). 
Após a quantificação dos dados da análise macroscópica da nascente urbana do córrego Villa City, eles foram qualificados com a finalidade de mitigar as alterações antrópicas ali constatadas. Diante disso, os alunos perceberam que, para evitar ou conter tais impactos, seriam necessárias algumas mudanças de atitude e que isso poderia refletir na qualidade de vida da população.

Mediante a todos os impactos socioambientais registrados e observados na área de estudo, os educandos foram expondo e debatendo as possíveis soluções para cada problemática, as quais foram separadas por área, sendo elas: Água; Resíduos; Vegetação; Erosão; Utilização.

A presença da professora exerceu um papel muito importante nessa etapa como mediadora e organizadora das ideias e dos debates. Os alunos, então, puderam entrar em um consenso e uma solução geral para recuperar e preservar cada problemática apontada na área de estudo, conforme Tabela 4.

Como estratégia de divulgação da proposta de EA, os alunos elaboraram mapas mentais, charges e frases de efeitos para espalhar pela escola, a fim de aguçar os demais colegas com base na caracterização geoambiental da área de estudo da nascente urbana do córrego Villa City. Os participantes dessa atividade se responsabilizaram em orientar e instruir os outros colegas da escola sobre o trabalho realizado. Outra estratégia foi elaborar um folder para auxiliar especificamente na divulgação nas redes sociais, a fim de atingir maior grau de visibilidade, conforme Figura 10.

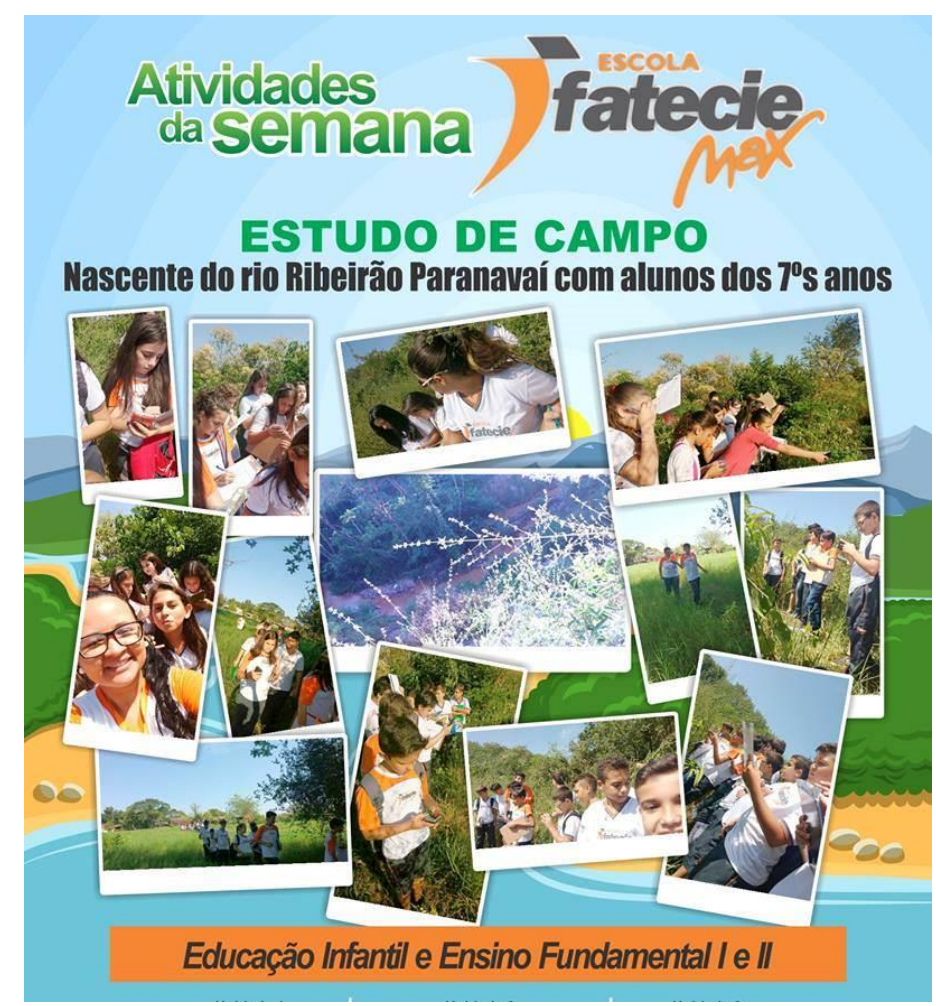

Figura 10: Folder de divulgação nas redes sociais.

Fonte: Autores (2018). 
Tabela 4: Qualificação da análise macroscópica da nascente urbana e seu entorno do Córrego Villa City e possíveis soluções.

TEMA

ÁGUA $\quad$ A nascente foi tubulada juntamente da galeria pluvial, apresenta cor clara e um cheiro leve de material orgânico em decomposição. Não foi detectada a presença de esgoto doméstico nas mediações, assim como a inexistência da presença de óleos e espumas.

RESÍDUOS Há grande ocorrência da presença de entulhos, principalmente de construção. Além de resíduos sólidos domésticos (plástico, papel, metal, vidro e etc.), o escoamento do fluxo superficial pode contribuir diretamente para a presença de lixo no local, primordialmente, em períodos de chuvas intensas.

VEGETAÇÃO A vegetação é típica da Floresta Estacional Semidecidual (que perde parcialmente as folhas em determinada estação do ano), a qual foi densamente degradada, como é possível verificar na figura 10, e algumas espécies nativas foram sendo substituídas por Ricinus communis (mamona), Brachiaria decumbens (capim brachiaria).

EROSÃO O processo erosivo encontrado no local é caracterizado como voçocora e suas margens são bastante íngremes, além de contribuir com a perda de solo para o processo de assoreamento do córrego, o alto fluxo superficial contribui para o desenvolvimento da erosão.

UTILIZAÇÃO A área é utilizada por animais em busca de pastagens, isso se tornou evidente ao presenciar pegadas e fezes de ruminantes no entorno, na vertente leste da erosão. As casas da população não ultrapassam 50 metros, sendo evidente que algumas residências foram abandonadas pelo avanço da Fonte: Autores (2018).

\section{POSSÍVEIS SOLUÇÕES}

Promover a conscientização da população sobre a importância dos recursos hídricos urbanos, principalmente as nascentes, por meio de divulgação na mídia e nas redes sociais, incentivados pelo poder público. Realizar monitoramento químico-físico da qualidade da água, a fim de realizar um diagnóstico mais preciso e implantar uma medida de recuperação mais direta.

Antes de realizar uma limpeza geral da área, seria necessário inicialmente conscientizar a população, principalmente do entorno, sobre o descarte correto dos seus resíduos, posteriormente realizar uma limpeza geral da área, desobstruindo galerias pluviais.

Restaurar a vegetação nativa com auxílio de órgãos competentes e população local. Antes, seria necessário realizar estudos sobre as características da flora local, a fim de contribuir para regeneração de um ambiente equilibrado.

Realizar obras de infraestrutura pública acima da área da voçocora, a fim de minimizar o escoamento e a enxurrada, que contribuem para o avanço da erosão. Retirar os ruminantes e regenerar a vegetação, além do isolamento da área.

Realocamento da população que ocupa área de risco, retirada de ruminantes, realização de delimitação e identificação da área. 
Ao final da aplicação, os alunos participantes escreveram um breve relato sobre a experiência de EA, como: "Eu achei super legal, pois, em vez de ficar só lendo sobre assunto, fomos lá, vimos, analisamos, discutimos diversos pontos e percebemos que algumas mudanças de hábitos podem contribuir para um ambiente mais equilibrado" (aluna A). "Na prática eu pude perceber que a população deve caminhar junto do poder público para ter uma vida melhor, um só mudar não resolve, é preciso ser os dois juntos" (aluno B). "Pude ver que as pessoas que mais sofrem com os problemas ambientais são os mais pobres" (aluno C).

A problemática encontrada na área de estudo está presente em um bairro periférico, nas mediações da nascente, na encosta da erosão e em áreas mais propensas a alagamentos, as quais são ocupadas por classes sociais com menor poder aquisitivo (situação percebida pelo aluno C).

Segundo Coelho (2006), os problemas ambientais não atingem igualmente todo o espaço urbano. Atingem muito mais os espaços físicos de ocupação das classes sociais menos favorecidas.

Os depoimentos acima evidenciaram a importância da EA no espaço formal como tema transversal, levando os educandos à reflexão sobre a sua postura enquanto cidadão atuante na sociedade.

\section{Conclusões}

A EA é um tema transversal e deve ser abordada de forma paralela ao conteúdo curricular da educação básica. Para isso, o professor pode fazer uso de metodologias de ensino mais atrativas, despertando a participação e assimilação mais assídua dos educandos.

A proposta exposta neste trabalho levou a reflexão sobre os impactos socioambientais da nascente urbana do córrego Villa City do município de Paranavaí-PR por meio de uma análise macroscópica em uma aula de campo.

Com esse estudo, os alunos puderam compreender a realidade onde vivem, destacando potencialidades e fragilidades do espaço geográfico.

O conhecimento científico proporcionou argumentos para destacar os aspectos da problemática presente na área de estudo e para propor soluções, além de induzir os educandos a participarem de discussões, em que se evidenciou a mudança de pensamento dos alunos, sendo notável a presença de uma visão mais crítica sobre os impactos socioambientais.

As atividades de EA potencializaram de forma positiva o processo de ensinoaprendizagem, além de proporcionar ao educando um conhecimento, por meio da observação e da investigação, que é essencialmente útil para compreender a realidade em que vive e o seu papel da sociedade. 
Agradecimentos: Ao Conselho Nacional de Desenvolvimento Científico e Tecnológico (CNPq), pelo apoio financeiro à pesquisa; à Universidade Estadual de Maringá; à Universidade Estadual do Paraná - Campus Paranavaí. Em especial à Escola Fatecie Max de Paranavaí, que possibilitou a aplicação deste projeto.

\section{Referências}

AMARAL, R.; RIBEIRO, R.R. Inundações e enchentes. In: TOMINAGA, L. K., SANTORO, J. e AMARAL, R. (orgs). Desastres naturais: conhecer para prevenir. São Paulo: Instituto Geológico, 2009.

BARTH, F. T. Aspectos Institucionais do Gerenciamento de Recursos Hídricos. In: Águas doces no Brasil: Capital Ecológico, uso e conservação. São Paulo: Escrituras, 1999.

BIELLA, C.A. COSTA, R.A. Análise Da Qualidade Ambiental Das Nascentes Urbanas De Caldas Novas - Go. VI Simpósio Nacional de Geomorfologia/ Regional Conference on Geomorphology, Goiana, 2006.

BRASIL. Sistema Nacional de Unidades de Conservação da Natureza, Lei 9.985 de 18 de julho de 2000.

BRASIL. Resolução CONAMA no 303, de 20 de março de 2002. Ministério do Meio Ambiente, 2002.

COELHO, M.C.N. Impactos Ambientais em Áreas Urbanas - Teoria, Conceito e Método de Pesquisa. In: GUERRA, A.J.T. CUNHA, S.B. (Org.) Impacto Ambientais Urbanos no Brasil. Rio de Janeiro: Bertrand, 2006. p. 19-45.

FILHO, J.C.L.S. Socioambiental: o perigo da diluição de dois conceitos. Revista eletrônica de Gestão Organizacional, vol. 5; n. 2; maio-agosto 2007. UFPE. p. 202-222.

GOMES, P.M.; MELO, C.; VALE, V.S. Avaliação dos impactos ambientais em nascentes na cidade de Uberlândia-MG: análise macroscópica. Sociedade \& Natureza, Uberlândia, 17 (32): 103-120, jun. 2005.

IPARDES. Caderno Estatístico - Munícipio de Paranavaí. 2018.

MAACK, R. Geografia física do Estado do Paraná. Ed. UEPG. 4ª Ed. 2012.

PLANO DIRETOR DE PARANAVAí, Ambiens Cooperativa, Paranavaí, 2009.

SANTOS, M. Técnica, Espaço e Tempo. São Paulo: Hictec. 1994.

SANTOS, E.C. Tranversalidade e áreas Convencionais. Manaus: UEA Edições: Editora Valer, 2008.

STIPP, M. E. F. A Ocupação do Solo e a Problemática da Arenização e Voçorocamento no munícipio de Paranavaí-PR. Tese (Doutorado em Geografia). Universidade de São Paulo. São Paulo, p. 176. 2006.

TUCCI, C. E. M. Águas urbanas. Estudos Avançados, v.22, n.63, p.1-16, 2008. 